\title{
Pharmacology, Biologicals
}

National Cancer Institute

\section{Source}

National Cancer Institute. Pharmacology, Biologicals. NCI Thesaurus. Code C18936.

The pharmacology of biologics. 